\title{
Review on Item Selection for Development of the Self-Reported Questionnaire Related to Lower Back Disorders at Workplace
}

\author{
Nur Atifah Jaffar and Mohd Nasrull Abdol Rahman* \\ Department of Manufacturing and Industrial Engineering, Faculty of Mechanical Engineering and \\ Manufacturing, Universiti Tun Hussein Onn Malaysia (UTHM), 86400 Batu Pahat, Johor, Malaysia
}

\begin{abstract}
This paper reviewed the current method in item selection available for developing self-reported questionnaire related to low back disorders at workplace. A systematic review of the literature was performed by searching using database and the searching strategy employed combined keyword for self-reported questionnaire, item selection, back disorders, and selection of items. Fourteen self-reported questionnaires related to low back disorders were review, there are different techniques implemented in selection of item in developing questionnaire. There are various techniques in selecting items in developing the questionnaire such as by surveying, correlation of item, factor analysis and by means of expert. Most of the self-reported questionnaire selected the items by survey technique based on risk factors related, where the previous self-reported questionnaires were reviewed and taken based on daily activities related to low back disorders. Thus, from the paper reviewed surveying technique were mostly used in selecting the item for the development self-reported technique with eight out of fourteen questionnaires. There are three self-reported questionnaires used in factor analysis to select the item and two self-reported questionnaires use item correlation technique to select the item for development of questionnaire. Only one self-reported questionnaire makes use of expert for selecting item in questionnaire development.
\end{abstract}

\section{Introduction}

Self-reported questionnaire is used to identify the status of functional and pain to subsequently evaluate the patients before and after treatment besides being used detect changes of systems and disabilities [1]. Self-reported functional disability is one of the most important outcome measurements in back pain research [2]. Those whom work in automotive industries commonly may be affected on various areas on the body such as back, wrists, arms, knees, hand, and neck [3]. Workers in wall plastering job were reported to experience discomfort in back regions [4]. People that always operate with computers or do other task in sitting posture commonly have experienced low back pain and

\footnotetext{
*Corresponding author: mnasrull@uthm.edu.my
} 
musculoskeletal injury [5]. The step in developing the questionnaire is based on international literature, stages of item selection, domain constructions and psychometric properties [6-9]. The committee of bilingual subject's matter experts (SMEs) [6] can be employed to determine the percentage of agreement score calculated for each questionnaire item [10]. Method of principal components analysis (PCA) is used to identify the items loaded in developing the questionnaire [11]. Criteria for the selection of the items in developing the questionnaire consist of conceptual and psychological [12]. Phase for item reduction is done by surveying with open-ended questionnaires selected from previous studies and from the important factor related to the case studies [13].

\section{Methods}

There are three stages of method used in reviewing the self-reported questionnaires which include selection of literatures from database, developing the evaluation criteria and evaluation process.

\subsection{Selection literatures from database.}

The literatures were explored using several of databases such as Science Direct, Google Scholar, Pub Med, Scopus, Seagate, and e-Journal to search and select a suitable references and related articles. The materials related were covered from 1980 until 2015.The combination of several keywords, terms, tittle, and abstract were screened and used in identifying journal related to Self-Reported Questionnaires for assessing the exposure of low back disorders.

\subsection{Developing the evaluation criteria.}

The evaluation criteria for these review methods contained the, items, questionnaire development and selection of item technique were evaluated.

\subsection{Evaluation process.}

The structure and content of evaluation process for selected publications were conducted by two researchers. The evaluation process will focus on the identifying the published questionnaires based on self-report method related to low back disorders from the previous case studies. The evaluation process involved finding any dissimilarities of information or gap to do documentations.

\section{Results}

According to the techniques for selecting the items in developing self-reported questionnaire that reviewed in ten self-reported questionnaires related to low back disorders is showed in Table 1. This table similarly describes the result in list of risk factors related to low back disorders for survey techniques, correlation value for item correlation technique, results for factor analysis technique and person whom observed as the expert in selection of 
items. Table 1 presents an overview of the item selection technique in developing questionnaire related to low back disorders.

Table 1. Item selection techniques in self-reported questionnaire related to low back disorders

\begin{tabular}{|c|c|c|c|}
\hline $\begin{array}{l}\text { Self-reported } \\
\text { questionnaire }\end{array}$ & Items & $\begin{array}{c}\text { Items selection } \\
\text { techniques }\end{array}$ & Result \\
\hline $\begin{array}{l}\text { Oswestry Disability } \\
\text { Scale (ODI) [14] }\end{array}$ & \multirow{3}{*}{$\begin{array}{r}10 \\
\text { items }\end{array}$} & \multirow{3}{*}{ survey } & \multirow{3}{*}{$\begin{array}{c}\text { Survey on the most relevant } \\
\text { problems in daily activities related to } \\
\text { low back disorders }\end{array}$} \\
\hline $\begin{array}{c}\text { Revised Oswestry } \\
\text { Disability Questionnaire } \\
{[24]}\end{array}$ & & & \\
\hline Modified Version [25] & & & \\
\hline $\begin{array}{c}\text { The Million Visual } \\
\text { Analogue Scale (MVAS) } \\
{[15]}\end{array}$ & $\begin{array}{r}15 \\
\text { items }\end{array}$ & $\begin{array}{c}\text { Item } \\
\text { correlation }\end{array}$ & $\begin{array}{c}\text { Intra and inter observer }(0.966 \\
\text { and } 0.918)\end{array}$ \\
\hline $\begin{array}{c}\text { Roland-Morris } \\
\text { disability questionnaire } \\
\text { (RDQ) [16] }\end{array}$ & $\begin{array}{l}24 \\
\text { items }\end{array}$ & survey & \multirow[b]{2}{*}{ Survey in aspect of daily living } \\
\hline $\begin{array}{l}\text { RDQ-23 } \\
\text { [28] }\end{array}$ & $\begin{array}{r}23 \\
\text { items }\end{array}$ & $\begin{array}{c}\text { Survey } \\
\text { based on } \\
\text { Sickness impact } \\
\text { profile }\end{array}$ & \\
\hline $\begin{array}{c}\text { RDQ-18 } \\
{[29]}\end{array}$ & $\begin{array}{r}18 \\
\text { items }\end{array}$ & $\begin{array}{c}\text { Item } \\
\text { correlation }\end{array}$ & 6 items were deleted \\
\hline $\begin{array}{l}\text { The Waddell disability } \\
\text { Index (WDI) }\end{array}$ & 9 items & $\begin{array}{l}\text { Factor } \\
\text { analysis }\end{array}$ & Total internal consistency is 0.76 \\
\hline $\begin{array}{c}\text { The Low Back } \\
\text { Outcome Score (LBOS) } \\
{[18]}\end{array}$ & $\begin{array}{r}13 \\
\text { items }\end{array}$ & Survey & $\begin{array}{l}\text { Survey on factor related to low } \\
\text { back disorders }\end{array}$ \\
\hline $\begin{array}{c}\text { The Low Back Pain } \\
\text { Rating Scales } \\
\text { (LBPRS) } \\
{[19]}\end{array}$ & $\begin{array}{r}25 \\
\text { items }\end{array}$ & Survey & $\begin{array}{l}\text { Based on Nordic Questionnaire } \\
\text { an daily task activities }\end{array}$ \\
\hline $\begin{array}{c}\text { The Clinical Back Pain } \\
\text { Questionnaire (CBPQ) } \\
{[20]}\end{array}$ & $\begin{array}{r}19 \\
\text { items }\end{array}$ & $\begin{array}{l}\text { Factor } \\
\text { analysis }\end{array}$ & 0.94 (correlated well) \\
\hline $\begin{array}{c}\text { The Quebec back pain } \\
\text { disability scale (QBPDS) } \\
{[21]}\end{array}$ & $\begin{array}{r}20 \\
\text { items }\end{array}$ & $\begin{array}{c}\text { Factor } \\
\text { analysis and } \\
\text { statistical } \\
\text { program } \\
\text { (TESTGRAF) }\end{array}$ & $\begin{array}{c}46 \text { items from } 48 \text { items by using } \\
\text { factor analysis and } 20 \text { items reducing } \\
\text { by using statistical program } \\
\text { (TESTGRAF) }\end{array}$ \\
\hline $\begin{array}{c}\text { The NASS Lumbar } \\
\text { Spine Outcome } \\
\text { Assessment Instrument } \\
\text { (NASS LSO) } \\
{[22]}\end{array}$ & $\begin{array}{c}62 \\
\text { main } \\
\text { question }\end{array}$ & $\begin{array}{l}\text { Expertise } \\
\text { person }\end{array}$ & $\begin{array}{l}\text { Group members from Task Force } \\
\text { evaluated the questionnaire. }\end{array}$ \\
\hline $\begin{array}{c}\text { Risk Factor } \\
\text { Questionnaire (RFQ) } \\
{[23]} \\
\end{array}$ & $\begin{array}{r}25 \\
\text { items }\end{array}$ & Survey & $\begin{array}{l}\text { Survey based on risk factors } \\
\text { related to lower back disorders in } \\
\text { form of four categories. }\end{array}$ \\
\hline
\end{tabular}




\subsection{Oswestry Disability Index (ODI)}

Oswestry Disability Index [14] questionnaire is an original paper with 10 items by surveying technique for the selection of items. The items are chosen by the most relevant problems that experienced by people with low back pain. This technique remains stagnant to two other versions of self-reported questionnaire which are Revised Oswestry Disability Questionnaire [24] and Modified Version [25] questionnaire and both of these questionnaires correspondingly haves same number of items which is 10 items. The entire self-reported questionnaire selected the items that are most relevant to daily activities that are related to low back disorders such as pain intensity, personal care, lifting, walking, sitting, standing, sleeping, sex life, social life and travelling.

\subsection{The Million Visual Analogue Scale (MVAS)}

The Million Visual Analogue Scale [15] is utilized to assess the disability and pain intensity in patients with LBP and consists of 15 items by using $100 \mathrm{~mm}$ Visual Analogue Scale (VAS). This questionnaire makes use of item correlations to select the item while developing the self-reported questionnaire. Item correlation was tested by using intra and inter observer. Intra-observer is observed by one person during collecting the data and the result for first trail is found to have high correlation of 0.966 . The inter-observer method is employed by using more than one person to observe the activities and give two trials to gain a high correlation of 0.918 . First trial of inter-observer failed due to the negative value for correlation in items number 3, thus the items was replaced in second trial for improvement.

\subsection{Roland-Morris disability questionnaire (RDQ)}

Roland-Morris disability questionnaire [16] is an original paper and modified sporadically and its newest version is Roland Disability Questionnaire-12 [26]. First version consists of 24 items by surveying technique from Sickness Impact Profile [27]. The items were selected based on daily living activities that used physical and mental function. The physical functions include walking, bending over, sitting, lying down, dressing, sleeping, self-care and daily activities. Another self-reported questionnaire was revised in Roland Disability Questionnaire-23 [28] by using similar techniques that reviews from the SIP [27] and has 23 items. Then, the previous questionnaire was revised again and forms the Roland Disability Questionnaire-18 [29] with 18 items by using item correlation techniques and consequently suggested that 6 items were deleted.

\subsection{The Waddell disability Index (WDI)}

The Waddell disability Index (WDI) [17] consists 9 items and items were selected based on factor analysis technique. Result from factor analysis showed that all the nine activities were well correlated. Nine activities in items listed are heavy lifting $(0.44)$, sitting one-half hour (0.44), travelling one-half hour (0.51), standing one-half hour $(0.51)$, walking one-half hour (0.65), sleep disturbance (0.61), social life restriction (0.62), sex life restriction (0.62) and help with footwear (0.54). All the nine activities have a total of internal consistency with high correlation which is 0.76 and $(r=0.70)$. 


\subsection{The Low Back Outcome Score (LBOS)}

The Low Back Outcome Score [18] to assess the patients with low back pain and consist of 13 items with 3, 6 and 9 point scoring system with survey techniques to select the items. The survey was based on factors related to low back disorders such as current pain, employment domestic chores, sport activities, resting, medical treatments or consultations, drug use, sex life and daily activities (sleeping, walking, sitting, travelling and dressing).

\subsection{The Low Back Pain Rating Scales (LBPRS)}

The Low Back Pain Rating Scales [19] was used to evaluate the clinical outcome of low back pain patients and consists of 25 items with VAS, (Yes/No) and NSAID scoring system. It's contains of three different components which are pain, disability, and physical impairment. These self-reported questionnaires used survey technique to select the items for develop the questionnaire. For pain section, the items was selected from the Nordic Questionnaire [30] based on a few parameters such as pain medication reduction, physical function, estimation and psychological adjustment [31]. For disability and physical impairment both of these section were surveyed based on daily task activities such as sleeping, ability to perform housework, walking, sitting, lifting, working, dressing, driving, running, getting up from the chair, climbing stairs, contact with people and expectations of future pain.

\subsection{The Clinical Back Pain Questionnaire (CBPQ)}

The Clinical Back Pain Questionnaire (CBPQ) [20] or Aberdeen LBP scale is used to measure of health outcome for patients with low back pain and it consists of 19 items with multiple choice and single choice answer. By employing the factor analysis techniques the item was selected for development this questionnaire. The item was reviewed from clinical literature item and it was devised from commonly used in the clinical assessment for patients with low back pain. Two measurements were used which are an internal consistency measured by Cronbah's alpha to measure the correlation between item and item-total correlation is to compare individual question with total score. Both of these measurements were considered as rejection as the total item-correlation is below 0.2. Thus, factor analysis was used to identify the health factors within the questionnaire. The result showed well correlation of 0.94 .

\subsection{The Quebec back pain disability scale (QBPDS)}

The Quebec back pain disability scales [21] is used to assess the degree of disability in patient with back pain and has 6-point difficulties scale as scoring system method used. This questionnaire consists about 20 items and the item was selected by using factor analysis technique and statistical program (TESTGRAF). 46 items were factor analysed from 48 items and decreased to 20 items by using statistical program (TESTGRAF) that was developed by Dr. J. Ramsay, Department of Psychology, McGill University, Montreal, Canada. The items were based on si domains which are bed/rest, sitting/standing, ambulation, movement, bending/stooping and handling large/heavy objects. 


\subsection{The NASS Lumbar Spine Outcome Assessment Instrument (NASS LSO)}

The NASS Lumbar Spine Outcome Assessment Instrument [22] aims to assess the instrument's reliability, validity and acceptability to the patients and consists of 62 main questions and was grouped into 5 categories which are group 1: Demographic data, Group 2: Medical history, Group 3: Pain, neurogenic symptoms \& function, Group 4: Employment history and Group 5: Data about outcomes of treatment. This questionnaire was derived from a consensus of the NASS and all the 62 questions obtained from 3 different existing questionnaires which are SF 36, modified ODI and modified employment assessment published by BIGOS. Within 18 months, expert in questionnaire which are Task Force group members were recruited to review the instrument and critique. Thus, it is observed the questionnaire became shorter, increase in readability, concise and simpler to follow.

\subsection{Risk Factor Questionnaire (RFQ)}

Risk Factor Questionnaire [23] focus to prevent extended disability, treat the acute and subacute stages of low back pain and employed 25 items of occupational risk factor questionnaires with Yes/No selection scoring system. The items were selected based on survey techniques. The selection of items from survey based on risk factors related to low back disorders such as load features (bulk or grip), handling activities (pushing, pulling, carrying), body position (sitting, climbing) and environmental demands (vibration, slippery surfaces, or work on elevated surfaces).

\section{Discussions}

There are 14 self-reported questionnaires related to low back disorders were reviewed in selection of items step. There are various techniques employed to select the item in developing the self-reported questionnaire which are by surveying either by revision from the previous study or by relating the risk factor of the case studies (low back disorders), item correlation, factor analysis and by using an expert to select the item. Basically, there are ten self-reported questionnaires related to low back disorders including Oswestry Disability Index (ODI) Version 1.0 [14], the Million Visual Analogue Scale (MVAS) [15], Roland-Morris Disability Questionnaire (RDQ) [16], the Waddell Disability Index (WDI) [17], the Low Back Outcome Score (LBOS) [18], the Low Back Pain Rating Scales (LBPRS) [19], the Clinical Back Pain Questionnaire (CBPQ) [20] or Aberdeen LBP scale, the Quebec Back Pain Disability Scale (QBPDS) [21], the NASS Lumbar Spine Outcome Assessment Instrument (NASS LSO) [22] and Risk Factor Questionnaire (RFQ) [23]. For Oswestry Disability Index (ODI) there are another two versions which are Revised Oswestry Disability Questionnaire [24] and Modified Version [25]. Both of the versions implemented similar techniques in selecting the items for developing the self-reported questionnaire. Other than that, Roland Disability Questionnaire had other versions a well which are RDQ-23 [28] and RDQ-18 [29] and both of these self-reported questionnaires also had same techniques for selection item in development of self-reported questionnaires which is by surveying technique based on SIP [27]. Most of the self-reported questionnaires use survey technique to select the item in development of self-reported questionnaire. The survey was taken based various characteristics which are established on daily activities, Sickness Impact Profile (SIP) [27] and based on risk factor related to low back disorders. There are 8 self-reported questionnaires that utilizing this method which are ODI [14], 
Revised ODI [24], Modified ODI [25], RDQ [16], RDQ-23 [28], LBOS [18], LBPRS [19] and RFQ [23]. 3 self-reported questionnaires which are WDI [17], CBPQ [20] and QBPDS [21] have used factor analysis method to select the item in development of self-reported questionnaire and 2 self- reported questionnaires which are MVAS [15] and RDQ-18 [29] had item correlation technique as the method to select the item for the development of selfreported questionnaires. There only one self-reported questionnaire that utilize expert to select the item in developing the self-reported questionnaire which is NASS LSO [22].

\section{Conclusions}

In this study, fourteen self-reported questionnaires related to lower back disorders were reviewed. There are four current techniques for selecting item in developing self-reported questionnaire related to low back disorders were reviewed and covered from 1980 until 2001, which are by survey, factor analysis, item correlation and by using expert. Most of the self-reported questionnaires selected the items by using surveying techniques which is ODI, RDQ, LBOS, LBPRS and RFQ. The most used survey techniques based on risk factors related to low back disorders which are ODI, LBOS and RFQ. Besides that, there are several self-reported questionnaires using techniques of surveying based on daily activities such as sitting, walking, standing, sitting, and bending which are RDQ and LBPRS. The least technique used among self-reported questionnaires is by using expert which is NASS LSO. 3 out of 14 self-reported questionnaires were found to use technique of factor analysis to select the item for development questionnaires. 2 out of 14 selfreported questionnaires were using item correlation method which are are MVAS and RDQ-18.

\section{Acknowledgement}

This research is funded by Office for Research, Innovation, Commercialization and Consultation (ORICC) and Universiti Tun Hussein Onn Malaysia (UTHM) under Geran Penyelidikan Pasca Siswazah (GPPS, Vot U745).

\section{References}

1. Grotle M, Brox JI, Vøllestad NK. Functional status and disability questionnaires: What do they assess? A systematic review of back-specific outcome questionnaires. Spine, 30, 130-140 (2004)

2. Deyo RA. Measuring the functional status of patients with low back pain. Arch Phys Med Rehabil 69,1044-53 (1988)

3. Rahman, M.N.A., Aziz, F.A. and Yusuff, R.M: Survey of body part symptoms among workers in a car tyre service centre. Journal of Human Ergology, 39 (1), 53-56 (2010)

4. Rahman, M.N.A., M.R.A. Rani, and M.J. Rohani: Investigation of work-related musculoskeletal disorders in wall plastering jobs within the construction industry. WORK: A Journal of Prevention, Assessment and Rehabilitation, 43 (4), 507-514 (2012).

5. Rahman, M. N. A., Zakaria, N. H., Masood, I., Adzila, S., \& Nasir, N. F: Risk assessment for assessing the subjective occupant seating discomfort related office works. Information, 19 (7B), 3025-3030 (2016) 
6. Lynn, M.R., Determination and quantification of content validity. Nurs. Res. 35 (6) 382-385 (1986)

7. Streiner, D.L., Norman, G.R. Health Measurement Scales: a Practical Guide to Their Development and Use, second ed. Oxford University Press, New York (1995)

8. Turner, R., Quittner, A.L., Parasuraman, B.M., Kallich, J.D., Cleeland, C.S., Mayo/FDA Patient-Reported Outcomes Consensus Meeting Group, Patient-reported Outcomes: Instrument Development and Selection Issues, Value Health 10(Suppl. 2) 86-93 (2007)

9. Snyder, C.F., Watson, M.E., Jackson, J.D., Cella, D., Halyard, M.Y., Mayo/FDA Patient-Reported Outcomes Consensus Meeting Group. Patient-reported Outcome Instrument Selection: Designing a Measurement Strategy. Value Health 10(Suppl. 2), 76-85 (2007).

10. Tilden, V.P., Nelson, C.A., May, B.A. Use of qualitative methods to enhance content validity. Nurs. Res. 39 (3), 172-175 (1990)

11. Intermediate Care National Evaluation Team. A national evaluation of the costs and outcomes of intermediate care for older people. Final report. University of Leciester, (2006)

12. Leal, Rossana B., et al. "Development of a questionnaire for measuring health-related quality of life among children and adolescents with mouth breathing." American journal of rhinology 7 allergy 29 (6) 212-215 (2015)

13. Saab, Sammy et al. " Development of a disease-specific questionnaire to measure health-related quality of life in liver transplant recipients." Liver Transplantation 17 (5) 567-579 (2011)

14. Fairbank J, Couper J, Davies J et al. The Oswestry low back pain questionnaire. Physiotherapy 66, 271- 273 (1980)

15. Million R, Hall W, Nilsen KH, Baker RD, Jayson MI. Assessment of the progress of the back -pain patient- Volvo Award in Clinical Science. Spine 7, 204- 212 (1981)

16. Roland M, Morris R. A study of the natural history of low back pain- Part 1 . Development of a reliable and sensitive measure of disability in low back-pain-. Spine 30, 130- 140 (1983)

17. Waddell G, Main CJ. Assessment of severity in low-back disorders. Spine 9, 204- 208 (1984)

18. Greenough CG, Fraser RD. Assessment of outcome in patients with low-back pain. Spine 17, 36-41 (1992)

19. Manniche C, Asmussen K, Lauritsen B, Vinterberg H, Kreiner S, Jordan A. Low Back Pain Rating scale- validation of a tool for assessment of low back pain-. Elsevier Science 57 (3), 317-326 (1994)

20. Ruta DA, Garrant AM, Wardlaw D et al. Developing a valid and reliable measure of health outcome for patients with low back pain. Spine 19, 1887-1896 (1994)

21. Kopec JA, Esdaile JM, Abrahamowicz M et al. The Quebec back pain disability scalemeasurement properties-. Spine 20, 341- 352 (1995)

22. Daltroy LH, Cats Baril WL, Katz JN, Fossel AH, Liang MH. The North American spine society lumbar spine outcome assessment instrument: reliability and validity tests. Spine 21, 741-749 (1996)

23. Halpern N, Hiebert R, Nordin M, Crane M. The test - retest reliability of a new occupational risk factor questionnaire for outcome studies. Applied Ergonomics, 32(1), 39- 46 (2001) 
24. Hudson-Cook N, Tomes-Nicholson K, Breen A A revised Oswestry disability questionnaire. In Roland M, Jenner JR (eds) Back Pain: New Approaches to Rehabilitation and Education. Manchester: Manchester University Press, 187-204 (1989)

25. Fritz JM, Irrgang JJ. A Comparison of a modified Oswestry low back pain disability questionnaire and the Quebec back pain disability scale. Phys Ther, 81, 776-788 (2001)

26. Atlas SJ, Deyo RA, van den Ancker M, Singer DE, Keller RB, Patrick DL. The MaineSeattle Back Questionnaire: a 12-item disability questionnaire for evaluating patients with lumbar sciatica or stenosis. Results of a derivation and validation cohort analysis. Spine 28, 1869-1876 (2003)

27. Bergner, Marilyn et al. "The sickness impact profile: conceptual formulation and methodology for the development of a health status measure." International Journal of Health Services 6 (3), 393-415 (1976)

28. Patrick DL, Deyo RA, Atlas SJ et al. Assessing health-related quality of life in patients with sciatica. Spine 20, 1899-1909 (1995)

29. Stratford PW, Binkley JM Measurement properties of the RM-18: a modified version of the Roland-Morris Disability Scale. Spine, 22, 2416-2421 (1997)

30. Kuorinka, I., Jonsson, B., Kilbom, A., Vinterberg, H.. Biering-Sorensen, F., Andersson, G. and Jorgensen, K., Standardised Nordic questionnaires for the analysis of musculoskeletal symptoms. Appl. Ergonom., 18, 233-237 (1987)

31. Evans, James H and I. I Abbott Kagan. "The development of a functional rating scale to measure the treatment outcome of chronic spinal patients." Spine 11 (3) 277-281 (1986) 